\title{
DISERTACIONES
}

Tecnologías y métodos computacionales para la investigación en ciencias sociales y comunicación ISSN: $1856-9536$

Doi: https://doi.org/10.12804/revistas.urosario.edu.co/disertaciones/a.7933

Volumen 13, Número 2 / Julio-diciembre 2020

Versión PDF para imprimir desde

http://revistas.urosario.edu.co/index.php/disertaciones

Para citar este artículo: Collado Campos, A. N. (2020). La resignificación del discurso político por medio de memes: el caso de EpN. Anuario Electrónico de Estudios en Comunicación Social "Disertaciones", 13(2), 1-23. https://doi.org/10.12804/revistas.urosario.edu.co/disertaciones/a.7933

\section{LA RESIGNIFICACIÓN DEL DISCURSO POLÍTICO POR MEDIO DE MEMES: EL CASO DE ENRIQUE PEÑA NIETO}

The Resignification of Political Discourse through Memes: Enrique Peña Nieto's Case Study

A ressignificação do discurso político através de memes: o caso de Enrique Peña Nieto

Alejandra Nallely Collado Campos, Universidad Iberoamericana (México)

ale.collado.campos@gmail.com

Recibido: 29 de mayo de 2019

Aprobado: 08 de enero de 2020

Fecha de prepublicación: 22 de julio de 2020

\section{RESUMEN}

Los 'memes' se han convertido en una fuente de entretenimiento, información, denuncia y en aliados de la sociedad civil que emiten, comparten y hace circular la crítica política. En México, el sexenio presidencial de Enrique Peña Nieto (EPN) estuvo plagado de sucesos mediáticos que lo han hecho transitar, como figura política, del enaltecimiento y mediatización a su total detrimento y ridiculización mediante los memes. Se presenta una propuesta de análisis de discurso multimodal en memes de EPN difundidos en páginas de Facebook durante el proceso electoral mexicano, entre el inicio de las campañas presidenciales y la toma de poder del nuevo presidente. Como resultado del análisis, se clasificaron memes por su origen en: lingüísticos hegemónicos y visuales hegemónicos. Por su contenido, se clasificaron en: meme noticia, meme del ridículo, meme insulto y meme despedida. Se concluye 


\title{
DISERTACIONES
}

ESTUDIOS

Tecnologías y métodos computacionales para la investigación en ciencias sociales y comunicación ISSN: $1856-9536$

Doi: https://doi.org/10.12804/revistas.urosario.edu.co/disertaciones/a.7933

Volumen 13, Número 2 / Julio-diciembre 2020

Versión PDF para imprimir desde

http://revistas.urosario.edu.co/index.php/disertaciones

que los memes referidos registran las expresiones de distintas clases sociales sobre los errores de la clase política y en ellos se encuentra una resignificación cambiante y fluida que no mantiene el discurso de un solo lugar. Sus sujetos emisores politizan un discurso que circula y se codifica en lo mercantil y lo empresarial, decodificándose en cuestionamiento y oposición. Si bien su capacidad desestabilizadora no es total, su potencial no depende del meme en sí mismo, sino de un actor que idealmente puede usar al meme como vehículo de debate, expresión, manifestación y de crítica reflexiva hacia el poder público.

Palabras clave: memes, crítica política, Enrique Peña Nieto, discurso multimodal.

\begin{abstract}
"Memes" have become a source of entertainment, information, denunciation, and alliance in the civil society that broadcasts, shares, and circulates political criticism. In Mexico, the six-year presidential term of Enrique Peña Nieto (EPN) was plagued by media events that transformed him, as a political figure, from exaltation and media coverage to being completely damaged and ridiculed through memes. A proposal to analyze multimodal discourse is presented on EPN memes shared on Facebook pages during the Mexican electoral process, commencing with the new president's presidential campaign and assuming power. As a result of this analysis, memes were classified on the basis of their origin into hegemonic linguistics and hegemonic visuals. On the basis of their content, they were also classified as news memes, ridicule memes, insult memes, and farewell memes. These memes recorded the expressions of different social classes on the errors/shortcomings of the political class, and in them, we find a changing and fluid resignification that does not maintain the discourse of a single place. Those who share memes politicize a discourse that circulates, and it is codified in the commercial and business realms, further decoding itself in questioning and opposition. While its destabilizing capacity is not total, its potential does not depend on the meme itself but on an actor who ideally can use the meme as a vehicle for debate, expression, demonstration, and thoughtful criticism of public power.
\end{abstract}

Keywords: Memes, political criticism, Enrique Peña Nieto, multimodal discourse.

\footnotetext{
RESUMO

Os "memes" se têm convertido em uma fonte de entretenimento, informação, denúncia e em aliados da sociedade civil que emitem, compartilham e faz circular a crítica política. No México, o sexênio presidencial de Enrique Peña Nieto (EPN) esteve cheio de acontecimentos mediáticos que o têm feito transitar, como figura política, do enaltecimento e mediatização ao seu total detrimento e ridicularização mediante os memes. Se apresenta uma proposta de análise de discurso multimodal em memes de EPN difundidos em sites de Facebook durante o processo eleitoral mexicano, entre o início das campanhas presidenciais e a tomada de poder do novo presidente. Como resultado da análise, classificaram-se memes por sua origem em: linguísticos, hegemônicos e visuais hegemônicos. Por seu conteúdo se classificaram em: meme notícia, meme do ridículo, meme insulto e meme
} 


\section{DISERTACIONES}

\section{ESTUDIOS}

Tecnologías y métodos computacionales para la investigación en ciencias sociales y comunicación ISSN: $1856-9536$

Doi: https://doi.org/10.12804/revistas.urosario.edu.co/disertaciones/a.7933

Volumen 13, Número 2 / Julio-diciembre 2020

Versión PDF para imprimir desde

http://revistas.urosario.edu.co/index.php/disertaciones

despedida. Conclui-se que os memes referidos registram as expressões de distintas classes sociais sobre os erros da classe política e neles encontra-se uma ressignificação mutável e fluida que não mantém o discurso de um só lugar. Seus sujeitos emissores politizam um discurso que circula e se codifica no mercantil e o empresarial, decodificando-se em questionamento e oposição. Ainda que sua capacidade desestabilizadora não é total, seu potencial não depende do meme em si mesmo, mas de um ator que idealmente possa usar ao meme como veículo de debate, expressão, manifestação e de crítica reflexiva para o poder público.

Palavras-chave: memes, crítica política, Enrique Peña Nieto, discurso multimodal.

El argumento de esta tesis es que los memes que circulan en comunidades de Facebook, cuyo protagonista es el expresidente EPN, tienen la posibilidad de subvertir el discurso político dominante, resignificándolo en un nuevo discurso político de corte humorístico mediante la deconstrucción paródica y satírica de la figura presidencial, no obstante, las condiciones y dinámicas bajo las que estos discursos se reproducen por medio de los memes, pueden resultar en la reproducción del mismo discurso que se intenta subvertiry en la simulación de la participación política. En este artículo se propone el análisis del discurso multimodal para el estudio de memes políticos.

\section{¿Qué son los memes políticos y por qué son importantes?}

Los mensajes y la información de índole política y social que llegan a nosotros día a día cuentan con una variedad de vertientes, medios y soportes. La eficacia con la que se lleva a cabo la transmisión de esta información está relacionada con el canal, la estrategia y el lenguaje con los que se transfieren dichos mensajes. Dentro de este contexto, internet se erige como fuente de información, expresión, entretenimiento y debate. ${ }^{1}$ Los mensajes transmitidos por medio de diversas redes sociales ${ }^{2}$ en este medio cobran vital importancia en el proceso comunicativo diario. Este hecho se evidencia de manera particular si se hace referencia a los llamados 'memes'.

1 Para Castells (1997), internet "es la espina dorsal de las comunicaciones globales a través de ordenador: es la red que conecta entre sí a la mayoría de las redes de ordenador" (p. 417).

2 Según Fernández y Paniagua (2012), las redes sociales digitales son comunidades virtuales que informan e interconectan a personas con gustos e intereses en común, y "configuran una de las herramientas características en donde el usuario es el verdadero protagonista” (p. 2). Las redes sociales más populares al momento son, de acuerdo con lo que informa el periódico Excélsior en su versión digital (2016): Facebook, YouTube, Twitter, Google e Instagram (Ig), de mayor a menor popularidad, respectivamente. 


\section{DISERTACIONES}

Los memes son "unidades de transmisión cultural, o unidades de imitación” (Dawkins, 1976, p. 218) que transfieren información, se reproducen en un medio determinado transformándose durante el proceso y difundiéndose como un virus. En el contexto de internet, los memes han sido nombrados como imemes por parte de Vélez (2015) y definidos como "aquello que es retransmitido y modificado por los usuarios, constituyen una de las formas más fáciles de retransmitir humorísticamente críticas sociales" (Vélez, 2015, p. 130). ${ }^{3}$ Son producto de una socialización dada en entornos digitales específicos y, en el caso de la política, toman como base discursos oficiales ya construidos para resignificarlos y hacerlos circular en una adaptación de los discursos con un necesario toque humorístico y satírico que se encarga de desmentir y ridiculizar las versiones oficiales de los medios.

No obstante, su tiempo de vida, su velocidad de propagación, así como el espacio efímero en el que nacen - viven y mueren en cuestión minutos o días- generan un escenario en el que la información, imitación o discurso que intentan transmitir, en un afán puro de reproducirse como lo hace cualquier virus, se sitúe de manera superficial en su contexto. Los memes pueden reproducirse de manera veloz en cualquier medio digital y convertirse en referencias culturales permanentes en el imaginario de la ciudadanía. Esta velocidad, por supuesto, no siempre es tan beneficiosa, porque los memes también pueden desaparecer u olvidarse pronto si no generan el impacto necesario. A diferencia del cartón político o la fotografía política contestataria, la permanencia del meme y los discursos que resignifica se encuentra en juego a cada segundo que pasa.

EPN se convirtió, durante su sexenio (2012-2018), en un personaje central de los memes que circulan en fanpages ${ }^{4}$ y grupos de Facebook, situación que se fortaleció de manera paulatina desde su pre-campaña política, apoyada fehacientemente por los medios de comunicación oficiales, ${ }^{5}$ con una intencionada sobre-exposición, un triunfo incomprensible para los votantes y los subsecuentes errores de cada aparición pública. En cada caso, los memes políticos dedicados a este personaje han documentado cada suceso.

El objeto de estudio que aquí se presenta resulta de la mayor pertinencia académica y coyuntural en un momento en el que, tanto los procesos de comunicación, como los roles del medio, el mensaje, la audiencia y el sentido se han ido renovando de manera significativa a partir de la llegada de nuevas formas de comunicarnos. En este contexto, se están generando escenarios en los que el papel de los usuarios ocupa un lugar primordial, no solo por su modalidad activa, sino por la posibilidad de apropiación, resignificación y producción de contenidos y discursos, dentro de la cual se pueden situar a los memes.

3 Para efectos de esta investigación, será referido simplemente como meme, comprendiendo que hablamos de memes en Internet con imagen y texto. Esto con la finalidad de no confundir al lector con las distintas clasificaciones existentes.

4 En español: "página de fans", una modalidad de Facebook creada para empresas, comunidades, productos y figuras públicas. A diferencia de un perfil personal de Facebook, a una fanpage no pueden agregarse amigos, sino acumular seguidores, esto se logra cada vez que un usuario le da un like a la página. Cada like es un seguidor, un fan.

5 Como medios de comunicación oficiales comprendemos televisión, radio, periódicos o sitios de internet que tengan a todas luces una inclinación a favor de difundir a discursos hegemónicos sobre la situación política, económica y social de México. 


\section{DISERTACIONES}

Este tema es novedoso, actual y de relevancia en una coyuntura político digital en la que los contenidos producidos y modificados por usuarios se encuentra en auge, razón por la cual se hace imprescindible una mirada a los memes que tienen como protagonista a la figura de EPN, el expresidente menos popular y peor evaluado de la historia de México (Mitofsky, 2018).

El estudio de los memes de EPN permite clasificar propiedades, temas, lenguajes, significados y requiere que estos sean comprendidos como una fuente importante de información y de registro de los discursos hegemónicos/ contrahegemónicos que surgen en el proceso, estos han logrado apoderarse de diversos espacios en la cultura y el imaginario.

¿Qué es lo que transportan estos vehículos socializados, estas creaciones comunales sin autor específico? ¿Es la opinión pública, el chiste del día, el hartazgo convertido en sátira? ¿Qué es lo que hizo al expresidente Enrique Peña tan vulnerable a convertirse en meme? Estas son algunas de las interrogantes que conforman la presente investigación, que reconoce la importancia de los memes como vehículos resignificadores de los discursos hegemónicos, generadores de opinión pública y agentes de intervención crítica en temas públicos, que no están exentos de los peligros de cualquiera de las manifestaciones sociales de la era digital, y esto es, la tendencia a la pronta desaparición, al pronto olvido, y a la reproducción vacía de contenidos.

El objetivo de esta investigación es analizar el contenido discursivo de los memes de EPN que circularon en comunidades de Facebook durante el proceso electoral mexicano, entre el inicio de las campañas presidenciales (30 de marzo de 2018) y la toma de poder del nuevo presidente (1 de diciembre de 2018), para determinar qué tanto resignifican y subvierten el discurso político mostrado por los medios oficiales mediante la deconstrucción paródica y satírica de la representación de la figura presidencial.

Mediante el análisis del discurso multimodal aplicado en memes políticos dedicados a EPN se busca contribuir a los estudios de la Comunicación en un rubro que se encuentra todavía en construcción y tener un impacto considerable en la investigación de Comunicación Política.

\section{Historia conceptual del meme, clasificaciones y su vinculación con otros temas}

Conforme ha ido evolucionando el concepto de meme, se ha advertido en este un objeto de análisis semiótico con distintas complejidades, una manifestación mediática que, debido a su rápida propagación y evolución, es necesario conocer, seguir y registrar. Si bien nos encontramos ante un campo poco explorado, los hallazgos realizados en este ámbito brindan la posibilidad de conocer el proceso de construcción de conocimiento alrededor del meme. Los distintos tipos de abordaje ponen de manifiesto el origen y evolución del estudio de los memes de Internet, al mismo tiempo que ofrecen modelos de análisis, métodos y herramientas para su observación.

Como ya se había mencionado al inicio de este documento, el término 'meme' fue acuñado por Richard Dawkins para nombrar a una "unidad de transmisión cultural, o una unidad de imitación" (Dawkins, 1993, p. 218), bajo la idea de designar al equivalente de un gen de la genética, pero en la cultura. Si bien el debate conceptual ya había iniciado anteriormente con la exploración de la correlación entre le evolución biológica y la cultural (Popper, 1934; White, 1949; Campbell, 1974), fue Dawkins (1993) quien profundizó en la teorización del concepto, así, primero pensó en mímeme, palabra con raíz griega que significa "imitación, imitar, imitable", sin embargo, el autor buscaba un término que también sonara monosílabo, como la palabra "gen". Al final lo 


\section{DISERTACIONES}

ESTUDIOS

Tecnologías y métodos computacionales para la investigación en ciencias sociales y comunicación

abrevió como meme, argumentando que otra posible interpretación podría ser su relación con la palabra 'memoria' en francés: même. En términos generales, podemos comprender un meme como aquello que puede ser imitado o copiado, es decir, replicado.

Tal como recapitula Pérez Salazar, los memes en internet ya han sido ampliamente estudiados y analizados a nivel conceptual. Han sido caracterizados como unidades o memorias semánticas (Wilson, 1998; Lissack, 2004), como signos que aluden a elementos comunes dentro de una subcultura (Shifman, 2011), que van de la ironía al humor fácil (Shifman \& Thdwall, 2009) y con sus diferencias con el meme offline,${ }^{6}$ categoría de la cual se desprenden las siguientes clasificaciones (Danung, 2008):

- Modelos de propagación viral: memes copiados y transmitidos sin modificación, ni reinterpretación.

- Modelos meméticos (Shifman, 2011): memes reinterpretados.

Para Vélez (2013), los memes no suceden de manera separada, sino ligados a diversos fenómenos relacionados entre sí a través de un comportamiento viral, y sus resultados no son predecibles todo el tiempo, ya que la tecnología y el medio afectará la forma en la que se transmite la información. Esta información, en suma con la interpretación que se hace de esta, pueden presentarse en forma de videos, imágenes fijas o en movimiento, y en su mayoría incluyen la combinación de estos con texto y hashtags. ${ }^{7}$

Comprendiéndoles entonces como unidades replicadoras de información referentes a sucesos desarrollados en la vida pública de sociedades específicas, se puede considerar:

[...]su importancia como objetos para la interpretación y la discusión sobre ciertos contenidos informativos y acontecimientos de la esfera pública, donde figuras del espectáculo y funcionarios públicos se han visto afectados en lo que respecta a su actuar y percepción social (Romero, 2015, p. 3).

Desde la Comunicación, se considera al meme como un fenómeno que, por su naturaleza transdisciplinaria, se puede abordar y trabajar de múltiples maneras. Se trata de una noción que continúa siendo elaborada, con diversos sentidos y funciones sociales. Otros estudios en esta materia han propuesto la posibilidad de integrarlos como objeto de análisis de campañas políticas electorales, e incluso se han propuesto taxonomías para analizarlos, ya que son considerados como agentes de activismo en la red, importantes influencias en la opinión pública y armas de denuncia por medio del humor.

6 Si se entiende un meme como cualquier unidad cultural que sea compartida y/o copiada, es decir, replicada, se puede pensar en infinidad de memes culturales: La Gioconda, el arte pop de Andy Warhol, la 5ta. Sinfonía de Beethoven, las referencias que circulan de nuestras series favoritas, canciones y demás obras icónicas que han sido "heredadas" por influencia cultural, social o por otras personas.

7 Otros conceptos importantes referentes a memes: Memeplex, es una matriz de memes. Funciona como una matriz de ideas, costumbres y rasgos que habita en anfitriones humanos y no humanos y transmite su influencia de generación en generación por medio de la comunicación humana (Lull \& Neiva, 2011, p. 30). Holomeme: el repertorio cultural completo de las variaciones que presenta un meme determinado, incluyendo aquellas formas latentes o aún no expresadas (Durham, 1991). 


\section{DISERTACIONES}

Por otro lado, es importante subrayar que, hablar de una unidad cultural, como señala la definición más resumida del meme, implica el abordaje de algunas cuestiones necesarias para distinguir el meme de un "virus" o del "gen egoísta". Siguiendo a Pérez y Aguilar (2014), a diferencia de los genes y los virus (metáforas en las que se apoya Dawkins para ilustrar su argumentación), el meme no se auto-replica, sino que requiere de un grupo de sujetos que lleven a cabo su retransmisión, a partir de las motivaciones y satisfactores que ya han sido mencionados.

Así lo explican Lull y Neiva (2011): "Los genes se replican. Las personas imitan. Los genes no piensan sobre lo que están haciendo. Las personas, presumiblemente, sí piensan [...] las elecciones culturales son motivadas desde el comienzo" (p. 26). Según Pérez y Aguilar, y en relación con la Teoría Memética de Dawkins, la elección cultural del meme proporciona ventajas para el propio meme, pues será repetido y seleccionado una y otra vez, lo que lo mantiene vivo y fluyendo.

Para Morozov (2011), es importante que no se olvide el vehículo en el que los memes de internet se desenvuelven: "Los memes nacen libres, pero en todas partes están sujetos por cadenas, las cadenas de las agencias de relaciones públicas y los artistas autónomos” (Morozov, 2011, p. 23). De acuerdo con la visión del autor, suponer que los memes son una mera tendencia resulta ingenuo, ya que estos no se reproducen solo por "la acción de fuerzas naturales y autónomas" (Morozov, 2011, p. 181), sino porque la plataforma en la que se encuentran alojados lo permite, generándole ganancias y seguidores. Para Morozov, no hay mejor publicidad que los memes.

Entre los autores que han retomado definiciones, conceptos y clasificaciones para seguir aportando en la construcción del conocimiento sobre historia del meme y teorías meméticas podemos encontrar a Holdcroft y Lewi (2000), Sterenly (2006), Cocker, Finkelstein, Waissbluth (2008), Cardoso y Atwell (2011), Castaño, Börzsei, Takana (2013), Gostin, Gómez (2014), Bissolotti, Nogueira, Fialho y Cybis, Beck- Fernández (2015). Otras líneas de investigación y temáticas que tienen a los memes como objeto de estudio incluyen la reflexión sobre la autoría en los memes (Soha \& McDowel, 2016); estudios sobre memes y género trabajado por Miltner en 2014, por Piñeiro y Martínez, Ballesteros, Hohenstein y Kanai en 2016; reflexiones sobre memes y literatura (Bourrier, 2016) y la función pedagógica de los memes (Arango, 2014).

Desde este trabajo se les da especial valor a las nociones del meme inserto en la cultura digital de Shifman, quien también propone otras dimensiones meméticas como contenido, forma y postura, y evalúa las posibles trampas que se pueden hallar en el potencial memético. Una muestra de ello, se encuentra en un estudio realizado en 2010 junto con Kampf, en el que realizan un análisis cuantitativo y cualitativo combinado de 200 memes en You Tube del video "It Gets Better", a razón de los suicidios de adolescentes homosexuales que habían sufrido acoso homofóbico. La idea colectiva original de hacer estas versiones era exhortar a jóvenes a concientizar sobre la problemática, y de acuerdo con los autores, lo que se encontró en muchos de estos videos fue un entendimiento de las normas de la identidad colectiva hoy autonombrada LGBTTTIQ. ${ }^{8}$ Cuanto más se reproducía el meme con sus respectivas mutaciones, los participantes tendían a replicar la censura y las normas existentes, aunque también se identificaron dominios de subversión potencial, relacionados no solo con el contenido de los videos, sino principalmente con las formas facilitadas por los medios digitales.

8 Lésbico, Gay, Bisexual, Transexual, Transgénero, Travesti, Intersexual, Queer. 


\section{DISERTACIONES}

A esta complejidad del fenómeno es a la que se apunta en este artículo. Si bien las taxonomías ya creadas por los investigadores pioneros de este campo resultan útiles para situar el tipo de memes objeto de este estudio, en lo que refiere al entorno digital se hace necesario revisar casos concretos de investigaciones que han aplicado el análisis de memes al estudio de la realidad social, en este caso política. Para ello, es requerido conocer los antecedentes de aquellas investigaciones que se han dedicado a explorar las condiciones de surgimiento, apropiación y producción del discurso político en el contexto de la Social Media, información que se desarrolla en el siguiente apartado.

\section{Social media y discurso político}

Una cantidad significativa de las investigaciones encontradas en la revisión de la literatura apuesta por las redes sociales digitales como un vasto campo de estudio, sobre todo en lo que refiere a las formas en las que circula el discurso y se adapta a las nuevas plataformas. Así, existen investigaciones centradas en la relación entre movimientos sociales y social media (Cottle, 2011; Gerbaudo, 2012), en las acciones colectivas mediante las redes (Bennet \& Segerberg, 2012; Sargentini, 2015), la auto-organización y complejidad para analizar movimientos en redes (Borge-Holthoefer, 2011; Morer, 2012), estudios que muestran las ventajas existentes en estos nuevos medios para realizar activismo (Earl \& Kimport, 2011), así como el análisis de mensajes en conjunto con su dimensión social y los discursos (Lindgren, 2011; Boccaletti, 2006). Además de proponer metodologías para el análisis de las redes sociales, se presentan conclusiones que apuntan a la socialización definitiva de las tecnologías de la comunicación y la información, así como a la identificación objetiva de otro tipo de relaciones dentro de sistemas sociales específicos mediante el uso y apropiación de las redes sociales.

En estas investigaciones se brindan distintos enfoques teórico-metodológicos para el abordaje de esta temática y para su medición, de la misma manera que se habla de la necesidad de mantener una postura crítica con dichas metodologías y de ampliar la visión de adaptar ciertos procedimientos a las necesidades de la investigación en cuestión, siendo analíticos con sus riesgos. Las metodologías utilizadas en estos trabajos son: descripción/explicación de procesos, análisis de clave ecológica del sistema de medios, técnicas cuantitativas y cualitativas de recolección de datos, etnografía virtual, análisis comparativo de medios semiótico y discursivo, investigación documental y entrevistas.

El argumento central de los trabajos mencionados, en general, es el potencial para la organización colectiva que tienen internet y las redes sociales. Estas investigaciones analizan colectivos en línea, redes, grupos, plataformas y su acción organizada en internet, apuntan a la visibilización de problemáticas y a la generación de nuevas movilizaciones. Algunas de las categorías que se trabajan en estas investigaciones son: juventud, globalización, alternatividad, democracia, participación, movimientos sociales, discurso, activismo, política.

El eje nuclear que guía la literatura revisada apunta a la unidad entre actores individuales y colectivos, cuyas vinculaciones van más allá de su comunicación en el mundo digital, lo que trae como resultado la cohesión de sociedades duraderas, todo esto, mediante plataformas digitales. Esta vinculación se da en relación con preocupaciones comunes e identidades parecidas que tienen las mismas demandas. En este sentido, no es que la llegada de las redes sociales digitales haya hecho posibles estos movimientos o la proliferación de determinados discursos: son las mismas demandas, pero con nuevos medios y herramientas. Los movimientos sociales y los partidos políticos existentes han encontrado un espacio útil e importante en las redes sociales, en el que pueden beneficiarse en mayor medida los intereses de los diversos públicos y llegar con mayor facilidad a estos (Fernández \& Panigua, 2012). 


\section{DISERTACIONES}

Guzmán considera que las redes sociales son un reflejo de las tensiones existentes en el espacio público y privado. La autora distingue un discurso contingente y bifurcado que carece de centro, y apunta a la necesidad de nuevas formas de enunciación horizontales en las que no se pierdan las voces, sino que se sumen e interpelen a un discurso dominante (Guzmán, 2013), no obstante, reconoce que en las redes sociales los sujetos establecen acción política que constituye:

[...] una manifestación de los silenciados, de los excluidos del discurso [...] su esencia es la configuración

de un espacio propio que busca que aquellos invisibles, los silenciados, los desposeídos sean sujetos

parlantes y visibles (Guzmán, 2013, p. 73).

Para Rodríguez (2016), "el papel de las plataformas de redes sociales no solo ha sido fundamental para transformar la manera en la que nos informamos, sino también en la que nos manifestamos” (p. 43). Este mismo autor hace un listado de las movilizaciones en Twitter en México de 2009 al 2016, resultando al menos 60 movimientos registrados. Desde esta perspectiva, los espacios virtuales, y específicamente las redes sociales, son formas de organización de la acción política, de enunciación y posicionamiento.

Un rasgo general en las conclusiones de los trabajos que aquí se enuncian es el reconocimiento de las redes sociales como agentes activos para la recuperación de la ciudadanía en contextos determinados, dado el grado de confrontación de los temas y discursos que se difunden, modifican y reproducen con los discursos hegemónicos, caso que se puede ejemplificar con el uso social de memes. El análisis de plataformas como Facebook, Twitter e incluso Instagram son un tópico recurrente en las investigaciones a las que se hace referencia en este apartado. La forma y rapidez de la propagación del discurso es uno de los aspectos que más se aborda, ya que es una de las características dadas por el medio digital en el que se desenvuelven.

Si bien el optimismo resulta desbordante en muchos de los casos que fueron revisados, hay otros estudios que van surgiendo con una mirada más crítica hacia estos discursos y movimientos, toda vez que se ha visto el proceso y la evolución de procesos políticos ciudadanos que tuvieron su génesis en la Red. Específicamente, el trabajo de Gallardo y Enguix (2016), se encarga de desmitificar la posibilidad del desarrollo de un discurso político genuino a razón del desenvolvimiento de tres tendencias en el marco de los entornos digitales:

- La espectacularización informativa en los medios de comunicación (“la política es espectáculo").

- La personalización en los representantes políticos ("el mensaje es el político").

- La desideologización de los ciudadanos ("el espectador es cínico").

Estos autores apuntan a que el discurso que se genera en estos medios es superficial y banalizante, ya que no importa tanto lo que se diga como el hecho de participar en la red social, es decir, ser visto. Esto es categorizado bajo la etiqueta de pseudopolítica.

Debido a la velocidad con la que avanzan los estudios dedicados a la social media, los discursos en línea y la participación política en los nuevos medios, es posible que cada vez se vayan encontrando más críticas que apuntan a la pronta difuminación de la política online, en un momento en el que ya se ha podido ver cómo algunos movimientos generados en redes sociales fueron desapareciendo junto con su discurso crítico y movilizador ante los discursos oficiales en gran variedad de temas.

En este contexto, se hace más evidente la complejidad de la construcción de nociones que puedan ayudar a explicar estas transformaciones a nivel de realidad social, en la política y en lo que refiere al campo de la comunicación, desde el cual, el estudio de medios, mensajes y discursos se traduce en una necesaria multiplicidad de 


\section{DISERTACIONES}

ESTUDIOS

adaptación y creación de modelos de análisis, teorías y métodos que permitan comprender la disputa por el poder en los ciberespacios.

\section{Memes políticos y las figuras presidenciales}

El estudio de los memes en el ámbito político ha ido en aumento los últimos años, ya que contienen una profusión de perspectivas desde las cuales se pueden estudiar. Los estudios existentes sobre memes han tenido, generalmente, como objetivo demostrar que estos tienen funciones subversivas respecto a los discursos que las figuras presidenciales emiten mediante sus departamentos de comunicación y de los medios de comunicación de corte oficialista. Algunos de los contextos en los que estos memes han proliferado son las campañas presidenciales en Nigeria durante 2014-2015, la Primavera Árabe, el debate sobre el Estado de la Nación de España en 2015, las campañas presidenciales en Estados Unidos durante 2012 y los episodios mediáticos de EPN antes y durante su sexenio presidencial.

Otros estudios se centran en el desarrollo de memes específicos y siguen su nacimiento, desarrollo, evolución, analizando todos los elementos de sus discursos para hacer una interpretación de lo que estos generan en contextos políticos específicos. Enfatizan la importancia de las características del meme (como su velocidad de propagación y desaparición) como elementos imprescindibles para su éxito. La resignificación del discurso es recurrente en los argumentos de estas indagaciones.

La literatura localizada en cuanto a memes y figuras públicas se centra en el papel de estos en la elaboración de discursos públicos y populares sobre temas de injusticia social. Se acuñan conceptos nuevos y se recontextualizan otros para la construcción del conocimiento sobre meme: trolling (Borroughs, 2013), memenauta (González \& González, 2013), activismo hashtag (Huntington, 2015), LOLitics (Tay, 2012) y slacktivism (Kliger \& Thornson, 2015). Todos estos apuntan a la práctica de la creación, modificación y compartición de memes como una manera de hacer política desde la Red, democratizar el activismo en línea y subvertir el discurso dominante mediante el humor (Huntington, 2013).

Muchos de estos artículos se centran en un meme específico, teniendo suficientes elementos semióticos y discursivos para su desarmado, análisis e interpretación de un suceso y un contexto específico. Es el caso de Bayerl y Stynoy (2014), quienes analizan el discurso que se encuentra detrás del meme del "policía de gas pimienta" y de las distintas variaciones que este fue adquiriendo conforme su mutación y reproducción. La discusión está centrada en la democratización del activismo en línea mediante memes que, en este caso, protestan contra los actos abusivos de la autoridad estatal.

Otro caso de estudio centrado en un solo meme es el dedicado al "Napalm Accidental", cuyo objetivo es mostrar cómo los memes pueden expandir el significado de una imagen. Boudana, Frosh y Cohen (2017) argumentan, basados en Hariman y Lucaites, que "las imágenes icónicas pueden mejorar el compromiso cívico y la cultura pública". No obstante, reconocen que algunos memes sí podrían disolver y degradar por completo el significado original de una imagen y degenerar la cultura pública.

Más estudios en el campo de los memes son los realizados por Burroughs (2013), en el que se analizan memes que circularon durante las campañas presidenciales de 2012 en Estados Unidos, con la finalidad de mostrar que el trolling mediante los memes es una práctica cultural. Caso similar es el de Adegoju y Oyebode (2015), quienes analizan el papel de los memes durante las campañas electorales en Nigeria entre 2014-2015. Estos 


\section{DISERTACIONES}

autores exploran las pautas del humor en memes aplicando el modelo sociocognitivo de Van Dijk y la taxonomía del humor de Neuendorf, concluyendo que los memes tienen funciones subversivas respecto al discurso que los candidatos intentan mostrar.

Algunos otros sucesos en los que se han analizado memes con la finalidad de mostrarlos como elementos subversivos que involucran a la ciudadanía, es el caso de la Primavera Árabe, en la que Harlow (2013) se da a la tarea de analizar memes en Facebook para determinar su papel en este suceso histórico. Martínez y Piñeiro hacen algo similar durante la realización del Debate sobre el Estado de la Nación en España en 2015, para conocer el discurso de los partidos políticos españoles. Los autores analizaron memes de Twitter y consideraron su uso como una estrategia comunicativa potencial. También argumentan que el estudio de los memes constituye una aproximación novedosa a los temas políticos.

De acuerdo con lo que esta literatura muestra, los memes son mayormente considerados como una herramienta importante para la elaboración del discurso público sobre injusticias sociales. Se refiere constantemente a que tienen incidencia en la esfera pública y se abordan generalmente desde la semiótica, el análisis del discurso, retórica visual y teorías del humor. El texto paródico y satírico es comúnmente referido como una característica intrínseca de la creación de nuevos significados desde el meme, dentro de una "cultura viral" o "cultura memética" (Kumar, 2015). El análisis del humor es definitivamente una de las líneas recurrentes al estudiar memes (Vélez, 2015; Kumar, 2015), ya que, de acuerdo con estas perspectivas, con el uso del humor se puede crear una tensión entre poder y ciudadanos.

Otras perspectivas manifiestan que los memes son un objeto de estudio interesante debido a que por medio de ellos se puede estudiar la naturaleza cambiante de la participación ciudadana, tanto individual como colectiva (Huntington, 2015), se centran más en el proceso de construcción del significado analizando su composición y descomponiéndola en imagen, texto, y temas (McClure, 2016), o en su calidad de artefactos discursivos (Milner, 2013) poniendo énfasis en su capacidad de remezcla, fijeza y novedad.

Otra aportación, es la acuñación del término LOLitics (Tay, 2012), memes políticos que surgen en respuesta al discurso dado por los medios oficiales que favorecen a figuras políticas mediáticas. Son productos de la cultura popular que se encuentran insertos en el juego del poder del discurso. Tay considera que los memes tienen potencial para el establecimiento de la agenda periodística, la crítica política mediante la cultura popular y como parte del discurso ciudadano cotidiano.

En este mismo sentido se comprende el estudio que analiza memes de epN localizados en Facebook y Twitter, en el que se concluye que los memes pueden constituirse en formas de intervención en temas públicos por parte de la ciudadanía. Al igual que los autores que se han discutido en este apartado, Romero (2015) considera que los memes son una poderosa fuente de información, opinión pública, crítica y denuncia que favorece a la libre expresión y a la participación ciudadana.

De acuerdo con el contenido de los estudios aquí presentados, se comprende que los medios de comunicación oficiales privilegian el discurso hegemónico dado por el poder en curso. El proceso de producción del discurso resignificado se gesta desde otros medios, insertos en lo que Stuart Hall (1972) denominó una compleja estructura de dominación. Sin embargo, de acuerdo con el material analizado y recolectado, se puede decir que el discurso generado en los memes referentes a EPN no cumple una sola función. 


\section{DISERTACIONES}

ESTUDIOS

\section{Aspectos metodológicos}

Se buscaron y observaron páginas de Facebook que se describieran y autonombraran como páginas de memes de sátira política y que tuvieran contenidos referentes a EPN, dedicadas a parodiar y satirizar personajes de la política mexicana con énfasis en presidentes, expresidentes y candidatos a presidentes. Se fueron descartando de este estudio aquellas con menor actividad e interacción con los usuarios, hasta quedar solo tres de ellas: "Instituto del Meme Electoral", "Peña Nieto Traicionó El Pueblo Mx" y “Enrique Peña Nieto:”.

Los memes seleccionados para esta investigación tienen como protagonista a EPN y fueron difundidos durante el proceso electoral mexicano, entre el inicio de las campañas presidenciales (30 de marzo de 2018) y la toma de poder del nuevo presidente ( $1^{\circ}$ de diciembre de 2018) en las fanpages referidas, de las cuales se seleccionaron 10 memes bajo los siguientes criterios:

1. Tienen como personaje principal a EPN.

2. Se difundieron entre el 30 de marzo y el 1 de diciembre del 2018 en alguna de las tres páginas seleccionadas.

3. Se componen de elementos lingüísticos, imagen y tienen una cantidad considerable de reacciones, shares y comentarios, es decir, tienen un impacto en el medio en el que fueron compartidos.

4. Contienen cargas simbólicas y códigos propios de la cultura popular y la política mexicana.

Mediante este análisis se busca descomponer los elementos de los memes es sus aspectos lingüísticos, visuales y digitales, para entender la forma en la que usuarios y creadores de memes resignifican el discurso oficial. Se realiza una descripción de cada elemento para caracterizar gramática, expresiones, temáticas y capital cultural necesario para su comprensión, para después darle un sentido e interpretación a estos elementos mediante un análisis del discurso desde la perspectiva de los estudios culturales, comprendiendo los memes como una expresión de la cultura popular desde la intertextualidad del lenguaje, el discurso y en la interpretación cultural.

La problemática de la apropiación y resignificación del discurso en los memes, así como su potencial político son elementos que se encuentran presentes de manera importante en la literatura revisada. No obstante, es necesario cuestionar algunas de las premisas existentes respecto de sus significaciones y discursos, dado que los memes no siempre contrarrestan la ausencia de crítica desde los medios. Una de las discusiones principales en este trabajo respecto a los memes es que pueden ser compartidos sin un espíritu crítico o por mero entretenimiento, así como por popularidad, moda o búsqueda de likes.

Para ello, habrá que discernir entre los niveles de significación de los memes, ya que mientras algunos tienen la intención de realizar una crítica o una demanda certera, otros solo buscan el entretenimiento y la diversión. En todo caso, en este proceso de investigación existe la búsqueda por darle su justo valor a los memes y considerar que, ya sean chistes locales, opiniones líquidas, textos densos o discursos políticos reapropiados, existe en ellos una narración de la realidad política-social de México durante lo que fue el sexenio de EPN.

\section{La resignificación del discurso en los memes}

El discurso iconográfico sobre el cual se crean los memes de EPN proviene de imágenes y fotografías que han sido mayormente difundidas por medios de comunicación oficiales. Existen muchos otros casos en los que medios 


\section{DISERTACIONES}

ESTUDIOS

Tecnologías y métodos computacionales para la investigación en ciencias sociales y comunicación ISSN: $1856-9536$

Doi: https://doi.org/10.12804/revistas.urosario.edu.co/disertaciones/a.7933

Volumen 13, Número 2 / Julio-diciembre 2020

Versión PDF para imprimir desde

http://revistas.urosario.edu.co/index.php/disertaciones

alternativos o independientes buscan fotografiar momentos que sean susceptibles de crear memes, que puedan prestarse a la crítica o mofa de personajes políticos, en este caso, la figura presidencial.

Si en la fotografía política de los medios hegemónicos se puede encontrar la forma a través de la cual se representa a sí mismo el poder del Estado, en los memes que tienen como protagonistas a figuras públicas de la política se está tomando originalmente una representación dada por quienes ejercen el poder del Estado y están resignificándola, asignándole características que representan la visión de quien transforma y comparte el meme en cuestión.

Un ejemplo de lo que se expresa en párrafos anteriores, se muestra en la figura 1, compuesta por tres imágenes. La imagen 1 es la fotografía oficial de EPN a 90 días de su mandato emitida por los medios de comunicación de presidencia, las dos siguientes imágenes muestran la misma fotografía resignificada con la visión de quien la creó. En la foto 2 de esta figura se aprecia el intercambio de la banda presidencial por otra que contiene un personaje femenino de la serie animada "Ositos Cariñositos", 9 el personaje se llama "Alegrosita", la más tierna, alegre y femenina del grupo. Estas características son trasladadas a la figura presidencial debido a que se considera que carece de carácter. ${ }^{10}$
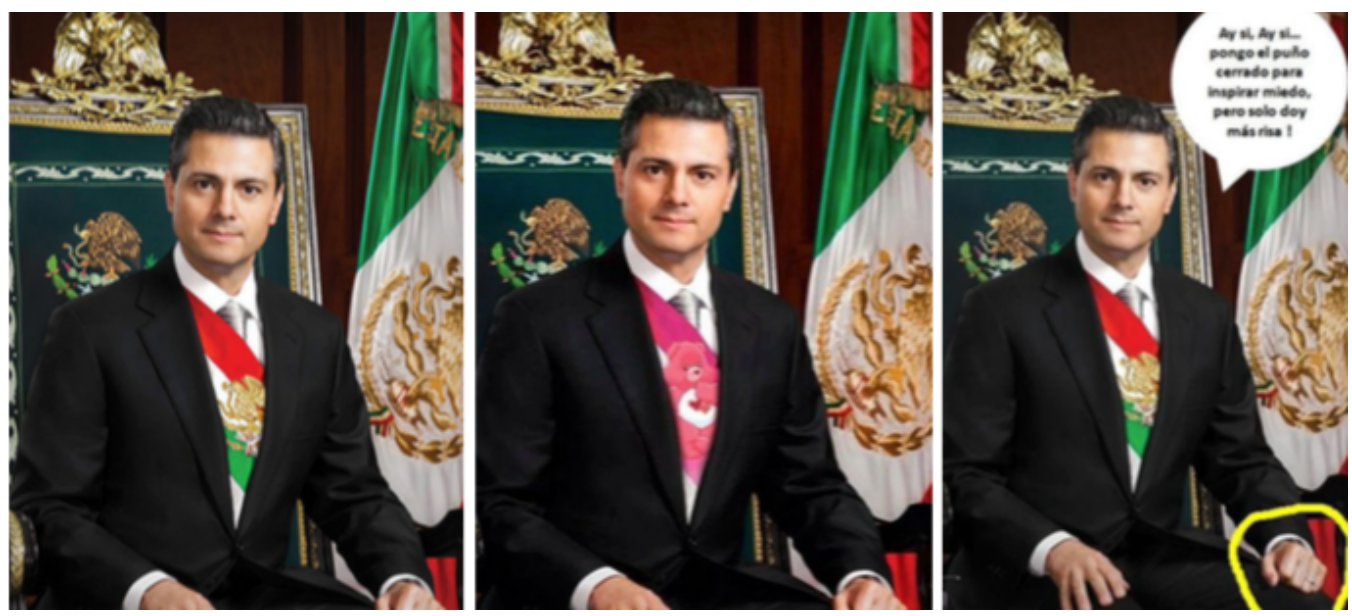

Nota: Imagen 1: Foto oficial publicada por los medios en marzo de 2013, a casi 100 días de haber iniciado su gobierno. Imagen 2. La misma foto, pero con la banda presidencial intercambiada por una banda de la serie animada "Los ositos cariñositos". Imagen 3. La misma foto, pero con un texto que alude a lo que le inspira el presidente a las y los ciudadanos.

Figura 1. Análisis de meme de EPN

Fuente: composición hecha a partir de imágenes en buscador de Google.

9 "Care bears" en su idioma original. Serie animada infantil de los años ochenta protagonizada por pequeños osos. Cada personaje tenía un poder relacionado con un color y un emblema distinto para cada uno, los portaban al frente, en el pecho y definían la personalidad de cada uno: "Alegrosita", "Generosita", "Gruñosito", "Revoltosito", "Divertosito" y "Tuercas".

10 Existe una imagen viral que circula en la red en la que aparentemente EPN, durante su juventud, porta un suéter con la misma imagen. No obstante, existe otra imagen, al parecer la original, en la que se muestra que la fotografía de dicho suéter de osito es Photoshop, y es la misma que se ha hecho circular como una imagen real con la intención de ridiculizarlo y darle las características ya mencionadas. 
Esta resignificación muestra connotaciones sexistas que descalifican lo femenino por parte de quien produce esta nueva versión de la imagen presidencial. En la imagen 3 se resignifica un elemento de la pose de EPN que probablemente pretendía significar fuerza y poder (el puño cerrado) y se acompaña con una frase memética: "ay sí, ay sí, ${ }^{11}$ pongo el puño cerrado para dar miedo, pero solo doy más risa”. Como se hace evidente en el análisis que se presenta, la carga semiótica de los memes, específicamente la de aquellos dedicados a EPN, es sumamente importante. Al respecto, algunas de las clasificaciones elaboradas durante la recolección y el análisis de memes de EPN, se explican a continuación.

\section{Por su origen}

\section{Meme de origen lingüístico hegemónico}

Retoman los elementos del discurso lingüístico oral o escrito dados por el discurso hegemónico para resignificarlo y combinarlo con otros memes populares. El discurso lingüístico es, muchas veces, un discurso dado por el mismo presidente, otras veces son frases de la cultura popular.

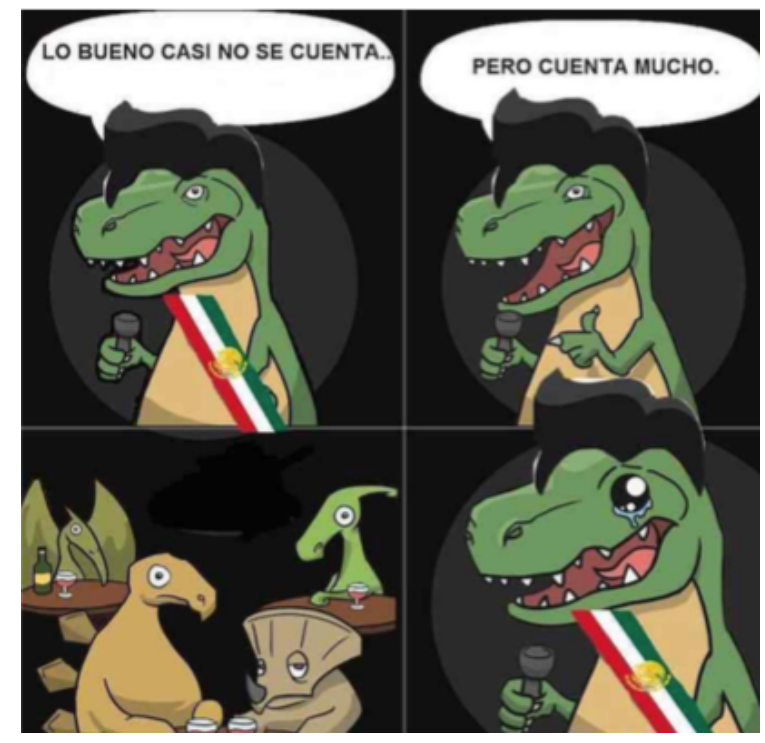

Figura 2. Meme del dinosaurio comediante

Fuente: Pinterest

11 Meme protagonizado por el científico Neil de Grasse Tyson en uno de sus videos de divulgación. En su idioma original el meme fue nombrado "We got a badass over here" (hablando de Isaac Newton) pero se tradujo como "ay sí, ay sí, soy muy chingón" en México, expresión utilizada generalmente para ridiculizar a una persona que presume más de lo que tiene o es, se puede ver en este enlacoehttps://www.youtube. com/watch?v=J7SdGxAZNMs 


\section{DISERTACIONES}

Tecnologías y métodos computacionales para la investigación en ciencias sociales y comunicación ISSN: 1856-9536

Doi: https://doi.org/10.12804/revistas.urosario.edu.co/disertaciones/a.7933

Volumen 13, Número 2 / Julio-diciembre 2020

Versión PDF para imprimir desde

\section{Meme de origen visual hegemónico}

Producen un discurso iconográfico que parodia al oficial combinado con discursos oposicionales. En el caso de EPN, generalmente se requiere tener ciertos referentes culturales y políticos para comprenderlo. El origen visual puede venir también de otra referencia de cultura popular.
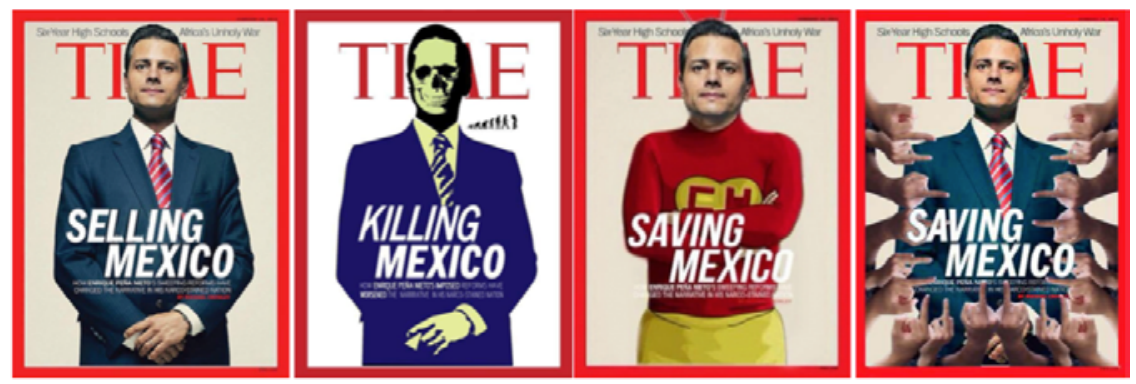

Figura 3. Parodia de la portada de la Revista Time, Edición 28, Febrero de 2014

Fuente: composición hecha a partir de imágenes en Know your meme

\section{Por su contenido}

\section{Meme noticia}

Muestra sucesos o aspectos de sucesos, en este caso relacionados con EPN, que no se mostraron en los medios oficiales. Tienen la finalidad de informar a la ciudadanía de manera sintetizada, y hacer una crítica mediante la burla. Es necesario conocer el contexto político para comprenderlos.
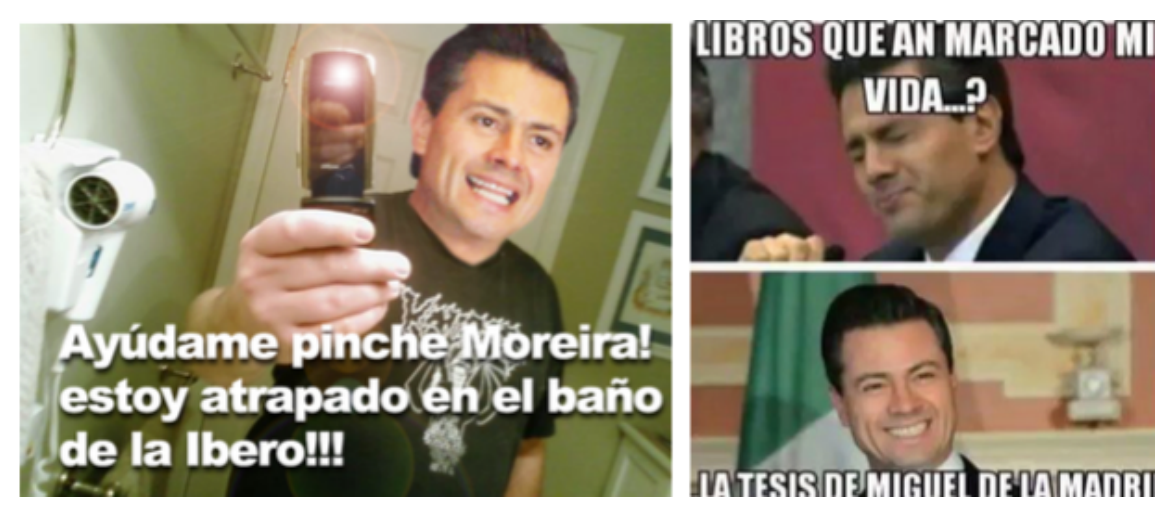

Figura 4. Memes relacionados con el suceso en la Universidad Iberoamericana el 11 de mayo 2012

Fuente: composición hecha a partir de capturas de pantalla en buscador de Google. 


\section{DISERTACIONES}

ESTUDIOS

Tecnologías y métodos computacionales para la investigación en ciencias sociales y comunicación ISSN: 1856-9536

Doi: https://doi.org/10.12804/revistas.urosario.edu.co/disertaciones/a.7933

Volumen 13, Número 2 / Julio-diciembre 2020

Versión PDF para imprimir desde

\section{Meme del ridículo}

Exalta los errores cometidos por EPN con frases e imágenes meméticas con la finalidad de criticar o burlarse. Generalmente son detalles de sucesos que ya han tenido un impacto mediático en los medios de comunicación oficiales.

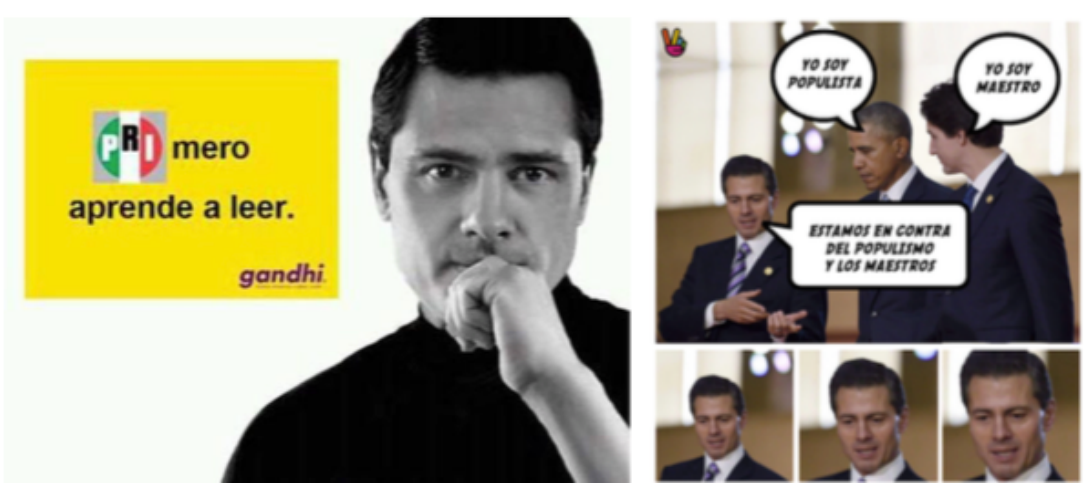

Figura 5. Imagen 1: Meme de Gandhi. Imagen 2: Meme de la visita de EPN a Canadá.

Fuente: composición hecha a partir de imágenes en Know your meme.

\section{Meme insulto}

Insulta y se burla por los rasgos físicos, la personalidad y la vida íntima de epN, así como de su gobierno.
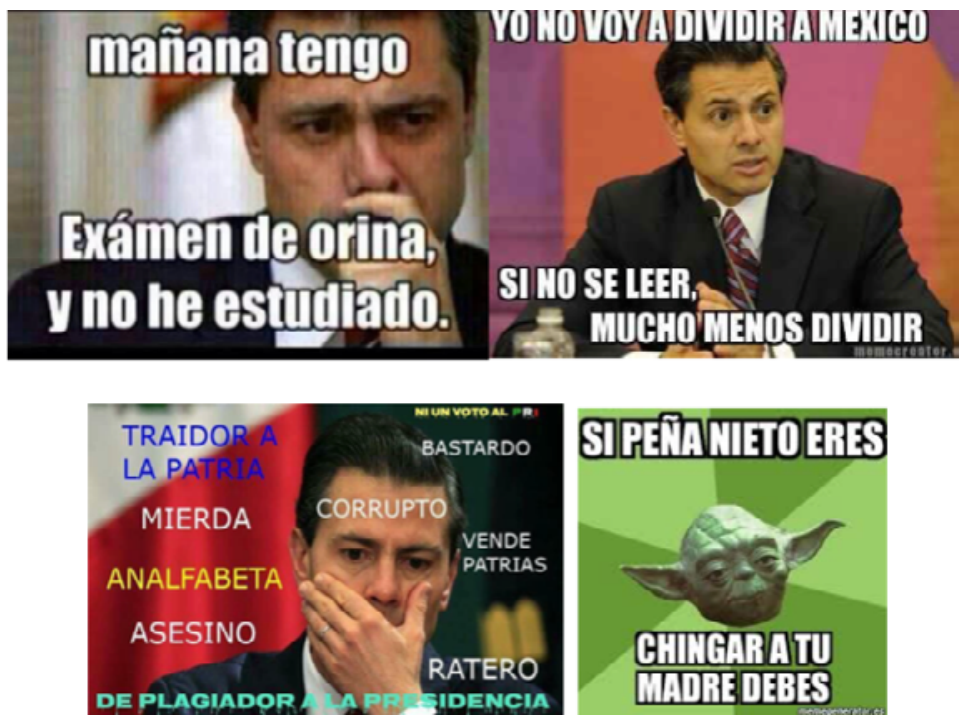

Figura 6. Memes que insultan a EPN

Fuente: composición hecha a partir de imágenes en buscador de Google. 


\section{Meme despedida}

Son aquellos memes que se crearon y difundieron desde que se supo el resultado de las elecciones presidenciales 2018, y los días circundantes a la toma de poder de Andrés Manuel López Obrador.
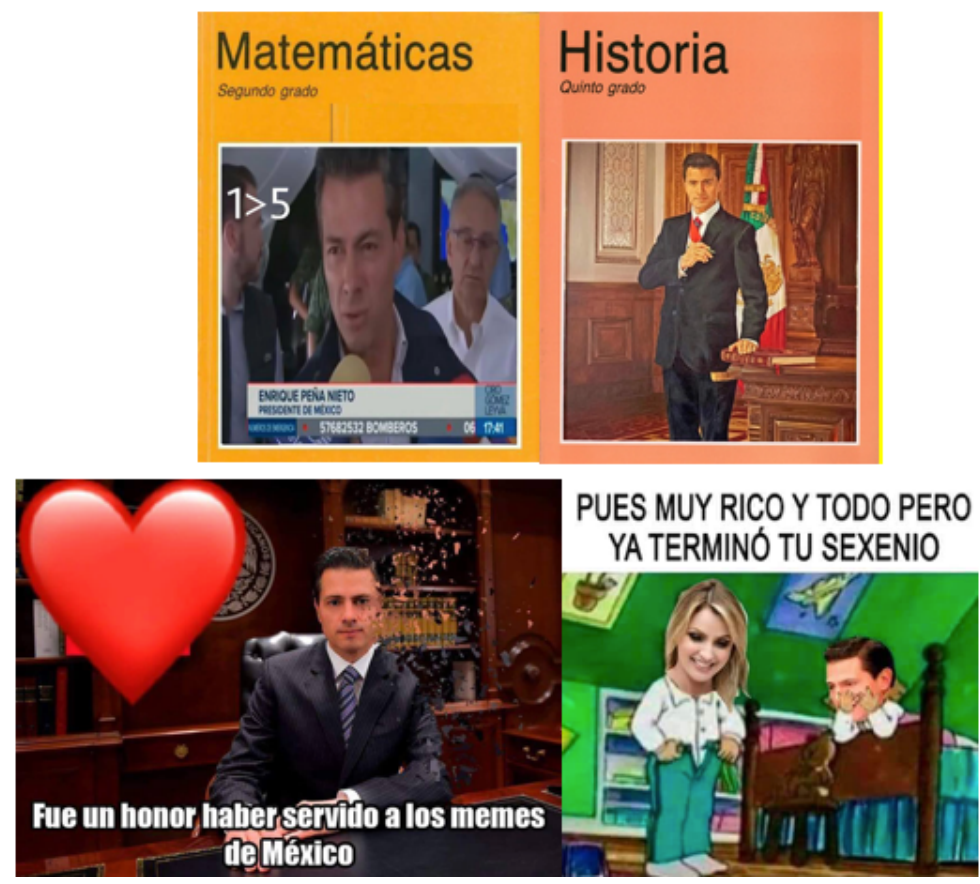

Figura 7. Memes que se despiden de EPN

Fuente: composición hecha a partir de imágenes en Facebook.

En general, con esta clasificación damos cuenta de que el discurso de los memes de epN se construye principalmente con referencias visuales y lingüísticas ya existentes, ya sean fotografías, frases, anuncios, canciones, refranes, portadas de libros, de discos, programas de tv, cine, etc. Todos ellos corresponden a sucesos reales acontecidos en la política mexicana, los memes construyen narrativas sobre estos sucesos y hacen que se mantengan en la memoria y la discusión pública. Los memes enfatizan esas frases, imágenes y personajes, es decir, les dan un carácter caricaturesco. Cada uno de estos memes es compartido en plataformas que interactúan con sus usuarios y reciben reacciones, comentarios y respuestas, muchas de ellas, también mediante memes que muestran burla, ironía, sarcasmo o indignación.

Durante este estudio también se hizo evidente que un meme puede dar origen a muchos otros memes: solo se requiere cambiar una palabra u omitirla, hacer una pequeña modificación en el contenido del meme y cambiarle completamente el sentido, de acuerdo con la postura de quien haga público el meme. 


\section{DISERTACIONES}

ESTUDIOS

\section{A manera de conclusión}

Los memes pueden ser considerados como la caricatura política en los tiempos de la era digital, como replicadores sociales que se contagian "de muro a muro" 12 y que informan en unos cuantos segundos acerca de la realidad de la semana, del día o del minuto. En los memes políticos "el humor es utilizado como forma de protesta, de contradiscurso frente al poder y figuras institucionalizadas" (Romero, 2015, p. 16). En este mismo sentido, Schmidt refiere que:

[...] el humor político es una forma de participación que destruyendo la seriedad, solemnidad, pompo-

sidad y ritualismo que envuelve a la política, resulta en perdida de respeto o de miedo para la política.

Reduce la capacidad de obediencia al poder y promueve la desmovilización” (Schmidt, 2006, p. 58).

Aquí cabe preguntarse: una vez pasado el auge de los movimientos en redes sociales ¿qué sucede con ellos? Si después del momento álgido de una movilización gestada por medio de las redes sociales en las cuales participa el meme como herramienta de registro y visibilización, se vuelve a la disolución de la realidad, a la individualidad, y a la estructura normal de dominación, ¿cuánto tiempo dura esa subversión en un contexto político específico? ¿cuánto tiempo dura en la agenda, en nuestras mentes?

Delia Rodríguez (2013) afirma que la memecracia es este entorno en la cual la viralidad gobierna, vista como una necesidad exacerbada de compartir y de ser vistos, en donde "en lugar de debatir públicamente sobre la realidad, lo hacemos sobre su sustituta: una competición de memes exaltados” (p. 123). Si bien el intento de cuestionar el discurso hegemónico es desestabilizar el bando en el que se encuentra el poder entrando en la dinámica de la resignificación del discurso, ¿el poder está cambiando de bando? ¿de qué manera está reconfigurando la participación política como práctica democrática en México?

En los memes de EPN circulados en Facebook durante el proceso electoral de 2018 en México se puede encontrar una resignificación cambiante y fluida que no mantiene el discurso de un solo lugar: política forjada desde una app móvil o desde una plataforma en línea, buscando el gesto más ridículo, la expresión más insulsa, el error más simple del día para caricaturizar al poderoso, al intocable, al que no se puede alcanzar en la vida corriente, la vida fuera de la esfera digital, como una existencia alterna.

Si la evolución de los memes los ha convertido en un vehículo que normaliza el discurso hegemónico debido a su viralización, si son un placebo que da la sensación de mantenernos en acción, habrá que reflexionar sobre el tipo de praxis en la que podría englobarse la creación de memes, más allá de considerar que la sola voluntad de hacer y compartir memes desarticula y desestabiliza el lugar del poder.

No obstante, por más líquida que sea la existencia de los memes, sigue atentando contra las estructuras existentes, la clase política y el presidencialismo. La viralización y el humor son estrategias provenientes de sujetos emisores que politizan un discurso que circula y se codifica en lo mercantil, lo empresarial (Facebook)

12 El "muro de Facebook" es el elemento central por medio del que se interactúa en Facebook. También conocido como timeline, el muro de cada usuario está personalizado de acuerdo con sus gustos, preferencias y amistades, y en él se muestran todos aquellos elementos que cada usuario comparte y que pueden ser vistos por amigos, amigos de sus amigos, o ser públicos, dependiendo de cómo se configure. 


\section{DISERTACIONES}

ESTUDIOS

Tecnologías y métodos computacionales para la investigación en ciencias sociales y comunicación

y se decodifica en el cuestionamiento y en la oposición. Los memes seguirán registrando las expresiones de distintas clases sociales, los errores de sus gobernantes y de más personas poderosas.

Tal vez su capacidad desestabilizadora no sea total, pero el potencial no depende del meme en sí mismo, sino de un actor que idealmente podría usar al meme como vehículo de debate, expresión, manifestación y de crítica reflexiva hacia el poder público. Los memes políticos son una extensión de nuestra cultura política, el contexto capitalista y neoliberal en el que surgen y se desenvuelven. La clave para distinguir entre sus distintos procesos está en la comprensión del contexto y de la presencia de un sujeto activo.

\section{Referencias}

1. Adegoju, A., \& Oyebode, O. (2015). Humour as discursive practice in Nigeria's 2015 presidential election online campaign discourse. Discourse Studies, 17(6), 643-662. https://doi.org/10.1177/1461445615602378

2. Aguilar, A., Castellanos, V., \& Pérez, G. (Ed.) (2013). La producción del conocimiento en las ciencias de la comunicación y su incidencia social. Recuperado de https://gabrielperezsalazar.files.wordpress. com/2013/06/20130607-libro-colectivo- amic-2012-final.pdf

3. Bayerl, P., \& Stoynov, L. (2014). Revenge by photoshop: Memefying police acts in the public dialogue about injustice. New media \& society, 18(6), 1006-1026. Recuperado de https://www.growkudos.com/publicatio ns/10.1177\%252F1461444814554747

4. Blackmore, S. (2000). La máquina de los memes. Barcelona, Paidós.

5. Börzsei, L. (2013). Makes a Meme Instead: A Concise History of Internet Memes. New Media Studies Magazine, (7), 2-28. Recuperado de https://works.bepress.com/linda_borzsei/2/

6. Boudana, S., Frosh, P., \& Cohen, A. (2017). Reviving icons to death: when historic photographs become digital memes. Media, Culture \& Society, 39(8), 1210-1230. https://doi.org/10.1177/0163443717690818

7. Bourrier, K. (2016). Victorian(ist) technologies. Victorian Studies, 58(2), 272-282. Recuperado de http:// www.jstor.org/stable/10.2979/victorianstudies.58.2.08

8. Burroughs, B. (2013). Obama Trolling: Memes, Salutes and an Agonistic Politics in the 2012 Presidential Election. The Fibreculture Journal, 257-276. Recuperado de https://www.researchgate.net/ publication/274697390_The_Fibreculture_JournalOb ama_Trolling_Memes_Salutes_and_an_Agonistic_ Politics_in_the_2012_Presidential_Election

9. Cardoso, G., \& Atwell, J. (2011). Directional cultural change by modification and replacement of memes. Society for the Study of Evolution, 65(1), 295-300. Recuperado de http://www.jstor.org/stable/27920049

10. Castells, M. (2003). Internet, libertad y sociedad: una perspectiva analítica. Polis, 4. Recuperado de http:// polis.revues.org/7145

11. Castaño, C. (2013). Defining and characterizing the concept of Internet Meme. CES Psicología, (6) 82-104. Recuperado de http://www.redalyc.org/articulo.oa?id=423539422007

12. Consulta M. (2018). Evaluación final del gobierno de Enrique Peña Nieto. Recuperado de http://www.consulta.mx/index.php/encuestas-e-investigaciones/evaluacion-de-gobierno/ item/1255-evaluacion-final-de-gobierno-enrique-pena-nieto-2012-2018 


\section{DISERTACIONES}

ESTUDIOS

Tecnologías y métodos computacionales para la investigación en ciencias sociales y comunicación ISSN: $1856-9536$

Doi: https://doi.org/10.12804/revistas.urosario.edu.co/disertaciones/a.7933

Volumen 13, Número 2 / Julio-diciembre 2020

Versión PDF para imprimir desde

http://revistas.urosario.edu.co/index.php/disertaciones

13. Dawkins, R. (1976). The selfish gene. United States. Oxford University.

14. Distin, K. (2005). The Selfish Meme: A Critical Reassessment. Cambridge: Cambridge University Press.

15. Echeverría, J. (2008). Apropiación social de las tecnologías de la información y la comunicación. Revista Iberoamericana de Ciencia, Tecnología y Sociedad - cTs, (4), 171-182. Recuperado de http://www.redalyc. org/articulo.oa?id=92441011

16. Gal, N., Shifman, L. \& Kampf, Z. (2015). It Gets Better: Internet memes and the construction of collective identity. New media \& society, 18(8), 1698-1714. https://doi.org/10.1177/1461444814568784

17. Gallardo-Paúls, B., \& Enguix, S. (2016). Pseudopolítica: el discurso político en las redes sociales. Departamento de Teoría de los Lenguajes y Ciencias de la Comunicación, Universitat de València. Recuperado de https://www. researchgate.net/publication/299284420_2016_Pseudopolitica_el_disc urso_politico_en_las_redes_sociales?enrichld=rgreq- 55326d5858f6458555f424a9d87882c5- XXX\&enrichSource=Y292ZXJQYWdlOzI5OTI4NDQyMDtBUzozNDIxNTg4MjY1OT AyMTBAMTQ1ODU4ODQyOTgzNQ\%3D\%3D\&el=1_x_3\&_esc=publicationCoverPdf

18. García, A. (2015). La explicación memética de la cultura. Revista de estudiantes de filosofía, Cuadrantephi (28). Recuperado de https://www.javeriana.edu.co/cuadrantephi/zona-articular/pdfs/N.28/La\%20evolucion\%20memetica\%20de\%20la\%20cultura\%20(Parametrizado).pdf

19. Giacaglia, M. (2002). Hegemonía. Concepto clave para pensar la Política. Tópicos. (10), 151-159. Recuperado de http://www.redalyc.org/articulo.oa?id=28801009

20. Gómez, I. (2014). Del meme al imeme, trascendiendo la dimensión lúdica. Entre textos, 5(10). Recuperado de http://entretextos.leon.uia.mx/num/15/PDF/ENT15-8.pdf

21. Gutiérrez, S., \& Cuevas, Y. (2012). Representaciones sociales de Enrique Peña Nieto, candidato a la presidencia de México 2012-2018, en la prensa escrita. Cultura y representaciones sociales, 7(13), 63-95. Recuperado de http://www.scielo.org.mx/scielo.php?script=sci_arttext\&pid=S2007-81102012000200003\&lng=es\&tlng=es.

22. Gunkel, D. \& Gournelos, T. (Eds.) (2012). Transgression 2.0. Los medios de comunicación, la cultura y la política de la era digital. Nueva York: Continuum.

23. Harlow, S. (2013). It as a Facebook revolution: Exploring the meme-like spread of narratives during Egyptian protest. Revista de Comunicación, (12), 59-82. Recuperado de http://udep.edu.pe/comunicacion/ rcom/pdf/2013/Art059-082.pdf

24. Hall, S. (1980). Codificar/decodificar. Culture, Media, Language. Working Papers in Cultural Studies. Londres, Routledge \& The CCCS University of Birmingham. Recuperado de https://comunicacionyteorias1. files.wordpress.com/2009/10/hall_s_codificar_decodificar.pdf

25. Häkkinen, A., \& Sirpa, L. (2013). YouTube Meme Warriors: Mashup Videos as Political Critique. Varieng, Vol. 15 - Texts and Discourses of New Media. Recuperado de http://www.helsinki.fi/varieng/series/volumes/15/ hakkinen_leppanen/

26. Holdcroft, D., Lewis, H. (2000). Memes, Minds and Evolution. Cambridge University Press, 75(292), 161-182. Recuperado de http://www.jstor.org/stable/3751809

27. Huntington, H. (2013). Subversive Memes: Internet Memes as a Form of Visual Rhetoric. Selected Papers of Internet Research. (14). Recuperado de http://www.academia.edu/5415739/Subversive_Memes_Internet_Memes_as_a_Form_of_Visual_Rhetoric 


\section{DISERTACIONES}

ESTUDIOS

Tecnologías y métodos computacionales para la investigación en ciencias sociales y comunicación ISSN: $1856-9536$

Doi: https://doi.org/10.12804/revistas.urosario.edu.co/disertaciones/a.7933

Volumen 13, Número 2 / Julio-diciembre 2020

Versión PDF para imprimir desde

http://revistas.urosario.edu.co/index.php/disertaciones

28. (2015). Citizen Meme: Hashtag Activism and Memes as Everyday Talk in the (Digital) Public Sphere. Department of Journalism \& Media Communication. Colorado State University. Recuperado de https://www. academia.edu/12267323/Citizen_Meme_Hashtag_Activism_and_Memes_as_Everyday_Talk_in_the_ Digital_Public_Sphere

29. Iedema, R. (2003). Multimodality, resemiotization: extending the analysis of discourse as multi-semiotic practice. Visual Communication, 2(1), 29-57. Recuperado de https://journals.sagepub.com/ doi/abs/10.1177/1470357203002001751

30. Juris, J., Pereira, I., \& Feixa, C. (2012). La globalización alternativa y los 'novísimos' movimientos sociales. Revista del Centro de Investigación, 10(37), 23-39. Recuperado de https://www.redalyc.org/articulo. oa?id=342/34223328002

31. Kliger, N., \& Thorson, K. (2015). Good citizenship as a frame contest: Kony2012, memes, and critiques of the networked citizen. New media \& society, 18(9), 1993-201. Recuperado de https://dialnet.unirioja.es/ servlet/articulo?codigo $=5692200$

32. Knobel, M., \& Lankshear, C. (2007). Online Memes, Affinities, and Cultural Production. A new literacies sampler. New York: Peter Lang. Recuperado de http://everydayliteracies.net/files/NewLiteraciesSampler_2007.pdf

33. Kumar, K. (2015). Contagious memes, viral videos and subversive parody: The grammar of contention on the Indian web. The International Communication Gazette, 77(3), 232-247. https://doi. org/10.1177/1748048514568758

34. Lull, J., \& Neiva, E. (2011). Hacia una nueva conceptualización evolutiva de la comunicación «cultural». Comunicar, Revista Científica de Educomunicación, 36(xvIII). Recuperado de http://www.revistacomunicar. com/verpdf.php?numero=36\&articulo=36-2011-04

35. Martínez, X., \& Piñeiro, T. (2015). Los memes en el discurso de los partidos políticos en Twitter: análisis del Debate sobre el Estado de la Nación de 2015. Communication \& Society, 29(1), 145-160. Recuperado de http://dadun.unav.edu/handle/10171/40180

36. McClure, B. (2016). Discovering The Discourse Of Internet Political Memes. Adult Education Research Conference. Recuperado de http://Newprairiepress.Org/Aerc/2016/Roundtables/12

37. Milner, R. (2012). The world made meme: discourse and identity in participatory media. (Tesis de Doctorado, Universidad de Kansas, Estados Unidos). Recuperado de https://kuscholarworks.ku.edu/bitstream/ handle/1808/10256/Milner_ku_0099D_122 55_DATA_1.pdf

38. Milner, R. (2013). Media Lingua Franca: Fixity, Novelty, and Vernacular Creativity in Internet Memes. Selected Papers of Internet Research, (14). Recuperado de https://journals.uic.edu/ojs/index.php/spir/ article/view/8725

39. Mozorov, E. (2014). To save everything, click here: The folly of technological solutionism. New York: Public Affairs.

40. Nogueira, H., Cybis P., Fialho, F., \& Bissolotti, K. (2015). Sites geradores de memes: O ócio criativo na internet. Razón y Palabra, (19), 1-18. Recuperado de http://www.redalyc.org/articulo.oa?id=199543036054

41. Pardo, N. (2012). Discurso en la Web: pobreza en YouTube. Editorial UN. 


\section{DISERTACIONES}

ESTUDIOS

Tecnologías y métodos computacionales para la investigación en ciencias sociales y comunicación

42. Pérez, G. (2014). Análisis de Redes Sociales: una introducción conceptual. Cuaderno núm. 2 de ensayos de comunicación, Educación y tecnología, vertientes entrelazadas, 7-21. Recuperado de https://www.academia.edu/7111605/An\%C3\%A1lisis_de_redes_sociales_Una_intr oducci\%C3\%B3n_conceptual

43. Pérez, G. (2014). El meme en redes sociales: prácticas culturales de la replicación en línea. Redes sociales digitales: nuevas prácticas para la construcción cultural, 113-132. Recuperado de https://www. academia.edu/10351363/El_meme_en_redes_sociales_Pr\%C3\%A1cticas_culturales_de_replicaci\%C3\%B3n_en_l\%C3\%ADnea"

44. Pérez, G., Aguilar, A., \& Guillermo, M. (2014). El meme en internet. Usos sociales, reinterpretación y significados, a partir de Harlem Shake. Argumentos, 27(75), 79-100. Recuperado de http://www.scielo.org.mx/ scielo.php?script=sci_arttext\&pid=S0187- 57952014000200005

45. Rodríguez, C. (2016). Política y ciberespacio: la transformación de la vida pública. Revista Proceso, (53), 38-37.

46. Rodríguez, D. (2013) Memecracia. Los virales que nos gobiernan. España: Editorial Gestión 2000.

47. Romero, L. (2015). Memes y opinión pública ¿una relación posible? Revista académica de la Federación Latinoamericana de Facultades de Comunicación Social, (91), 1-19. Recuperado de http://dialogosfelafacs. net/wp-content/uploads/2015/09/Dialogos91_MEMES_Y_OPINIoN_PuBLICA.pdf

48. Shifman, L. (2013). Memes in a digital world: Reconciling with a Conceptual Troublemaker. Journal of Computer-Mediated Communication, 18(3), I-II, 251-397. https://doi.org/10.1111/jcc4.12013

49. Shifman, L. (2014). The Cultural Logic of Photo-Based Meme Genres. Journal of visual culture, 13(3), 340358. https://doi.org/10.1177/1470412914546577

50. Shifman, L. (2013). Memes in Digital Culture. MIT Press. Recuperado de www.jstor.org/stable/j.ctt14bs14s

51. Tay, G. (2012). Binders full of LOLitics: Political humour, internet memes, and play in the 2012 US Presidential Election (and beyond). European Journal of Humour Research, 2(4) 46-73. https://doi.org/10.7592/ EJHR2014.2.4.tay

52. Tello, C. (2012). Enrique Peña Nieto. La senda del Rockstar. Nexos, Recuperado de https://www.nexos. com. $m x / ? p=14839$

53. Trejo, R. (2000). El imperio del marketing político. Cuando las imágenes desplazan las ideas. América Latina Hoy, Revista del Instituto de Estudios de Iberoamérica y Portugal, (25), 15-22. Recuperado de http:// revistas.usal.es/index.php/1130-2887/article/view/2642/2683

54. Valverde Vásquez, K. (2015) Cuenca dentro de las redes sociales. Los memes ¿un reflejo de nuestra cultura? Recuperado de http://dspace.ucuenca.edu.ec/bitstream/123456789/23981/1/TESIS.pdf"

55. Vélez Herrera, J. (2013). Memética como herramienta científica para el estudio de las memes de internet. Recuperado de https://www.academia.edu/6017507/La_mem\%C3\%A9tica_como_herramienta_cie nt\%C3\%ADfica_para_el_estudio_de_las_memes_de_Internet

56. Vélez, H. J. (2013). Los memes de Internet y su relación con la memética. Recuperado de https://www.academia.edu/5870278/Las_memes_de_Internet_y_su_relaci\%C3\%B 3n_con_la_mem\%C3\%A9tica 


\section{DISERTACIONES}

\section{ESTUDIOS}

Tecnologías y métodos computacionales para la investigación en ciencias sociales y comunicación ISSN: 1856-9536

Doi: https://doi.org/10.12804/revistas.urosario.edu.co/disertaciones/a.7933

Volumen 13, Número 2 / Julio-diciembre 2020

Versión PDF para imprimir desde

http://revistas.urosario.edu.co/index.php/disertaciones

57. Vélez, H. J. (2015). Influyendo en el ciberespacio con humor: imemes y otros fenómenos. Versión. Estudios de Comunicación y Política. Recuperado de http://bidi.xoc.uam.mx/resumen_articulo.php?id=10091\&archivo=7-696- 10091 lvu.pdf\&titulo_articulo=Influyendo\%20en\%20el\%20ciberespacio\%20con\%20 humor:\%20 imemes\%20y\%20otros\%20fen\%C3\%B3menos

58. Waissbluth, M. (2008). La máquina memética. Revista Qué Pasa. Recuperado de http://www.mariowaissbluth.com/secciones/articulos/pdf/maquina_memetica.pdf

59. Wiggins, B., \& Bowers, B. (2014). Memes as genre: A structurational analysis of the memescape. New media \& society. 17(11), 1886-1906. https://doi.org/10.1177/1461444814535194

60. Tanaka, Y. (2003). Meme Media and Meme Market Architectures: Knowledge Media for Editing, Distributing, and Managing Intellectual Resources. Wiley-IEEE Press. 